\title{
Examine the Relationship between Leadership Style (Based on Likert Theory) with Job Satisfaction of Teachers in Shahed High Schools' for Girls' in Tehran in the Academic Year 2014-2015
}

\author{
Mohammad Heydari \\ "Corresponding Author", Master of Business Administration in International Business student orientation, Payame Noor \\ University International Center of Assaluyeh, Iran, Postcode: 3168144444, Email: MohammadHeydari1992@yahoo.com
}

Mahdiye Saeidi

Master of Information Technology in knowledge management student orientation Payame Noor University, Unit of Tehran West, Iran. Email: mahdisan57@yahoo.com

Habibollah Danai

PhD in Business Administration and Professor, Payame Noor University, Tehran, Iran Email: h.danaei@live.com

Doi:10.5901/mjss.2016.v7n2s2p224

\begin{abstract}
In this study, job satisfaction of female teachers in shahed high schools' for girls', in the academic year 94 -93 Tehran's control measures and the relationship between job satisfaction with school leadership style based on leadership styles autocratic leadership style colonial Likert includes leadership autocratic benevolent, consultative and participatory leadership style leadership investigated. In this study, questionnaires were used to collect the information and the reliability of the questionnaire through Cronbach's alpha was calculated and used questionnaires include "leadership style questionnaire with reliability 0/8203", "Minnesota questionnaire validity and high reliability has been used."In this study, subjects using the "Morgan Takman" of the 201 teachers working in 11 shahed high schools' for girls', 133 people were witnessed. The results showed that the relationship between leadership styles and job satisfaction of teachers there. The relationship between autocratic leadership style / exploitation Likert's job satisfaction of teachers in the target population there. The relationship between authoritarian style - no exploitation Likert's job satisfaction of teachers. Positive relationship between job satisfaction of teachers Likert consultative leadership style there. Likert positive relationship between participatory leadership style and job satisfaction of teachers in the target population in the 2014-2015academic year is available.
\end{abstract}

Keywords: job satisfaction, leadership style, Likert theory, shahed high schools' for girls'

\section{Introduction}

Basically, the need to manage all the social context is necessary. No leadership worthy of the great human and material resources, the destruction is coming soon, but in the educational system due to the impact of education on all elements of society that the performance of a special sensitivity to other's management. The educational centers, more than any other institution dealing with human beings and the other hand on the transfer of cultural heritage from generation to generation, and preparing the ground for the cultural heritage of fertility, none of the elements of society, the role of teacher as foundation.

Efficiency and effectiveness of the education system depend on the effective and efficient management of the system. Due to the tremendous and unprecedented changes in the economy, politics, science and technology, particularly in recent decades occurred, is far broader and more complex tasks and management practices of the past. The only people who are professionally trained and have been brought up to this responsibility, effectiveness and efficiency will be able to perform the duties assigned to the same management as a profession today based on the features that is being considered. (Pardakhtchi, 1994, p. 55)

The need to use the talents and expertise of human resources, good atmosphere, good motivation and job satisfaction among them. Therefore, human resources, an important factor in the success and progress of any 
organization and no organization without it would not be able to achieve all their goals. (Hoy and Myskel, 1992, p. 18)

Considering the importance of leadership and management in schools and the importance of teachers 'job satisfaction as key elements in the school, in this study, job satisfaction of female teachers in shahed high schools for girls' in Tehran measure in academic year 94-93, and relationship satisfaction. Work with school leadership style based on the Likert leadership styles, including colonial autocratic leadership style, authoritarian leadership benevolent, consultative and participatory leadership style leadership investigated.

\section{Questions and Research Hypotheses}

\subsection{The main research question}

1. Does the leadership style of Likert view the job satisfaction of teachers in society, there is a significant statistical relationship?

\subsection{Secondary research questions}

1. Is the exploitative autocratic leadership style of managers with job satisfaction of teachers in society, there is a significant statistical relationship?

2. are the benevolent autocratic leadership style of managers with job satisfaction of teachers in society, there is a significant statistical relationship?

3. did the consultative leadership style of managers with job satisfaction of teachers in society, there is a significant statistical relationship?

4. are the participatory leadership style of managers with job satisfaction of teachers in society, there is a significant statistical relationship?

\section{Research Hypotheses}

\subsection{The main hypothesis of the research}

1. The Likert leadership style from the perspective of the job satisfaction of teachers in the target population, there is a significant relationship.

\subsection{Secondary research hypotheses}

1. Exploitative autocratic leadership style of managers with job satisfaction among teachers in the target population, there is a significant relationship.

2. The benevolent autocratic leadership style of managers with job satisfaction of teachers in the target population, there is a significant relationship.

3. Consultation between managers' leadership style and job satisfaction of teachers in the target population, there is a significant relationship.

4. Participatory leadership style of managers with job satisfaction among teachers in the target population, there is a significant relationship.

\section{Theory and Literature}

\subsection{Literature}

\subsubsection{Define leadership}

Leadership is the art or science of influence on the parties in accordance with their wishes in order to achieve the goals set by step. (Abbaszadegan, 1997, p. 28)

"George Tery" Leadership is about influencing people to act so that willingly strive for the goals of the group. (Hersey and Blanchard, To understand the meaning of leadership should consider three main variables:

(A) leader (the person who will change the behavior of others to benefit the organization and the goal) 
(B) The followers or subordinates (people who bring to bear on the organization of cooperation required)

(C) Environment (an environment with specific characteristics that require a team to achieve a common goal to work) (Abbaszadegan, 1997, p. 291)

Leadership means of attracting people and influence them so that people voluntarily accept personality and individual leaders in a certain situation. (Mir Kamali, 1999, p. 74)

\subsubsection{Defined Likert's leadership style}

"Likert" The study found that the most common styles of leadership can be shown on a continuum from one to four systems this system can be described as follows.

Authoritarian leadership system of exploitation: this kind of leadership to subordinates did not have trust and confidence in the process of decision-making because they rarely see. All decisions and targets through the chain of command at the helm done and taken down. These hands are forced by fear, intimidation, punishment, rewards incidental physiological and safety at work and satisfaction. Little interaction occurs between the supervisor, and subordinate are usually associated with fear and suspicion. Tight control process focused on the supreme leader is usually held under these conditions is a non-official which opposes the organization's objectives.

The two leader's benevolent authoritarian system: The first type of fatherly leadership is contrary to the confidence with such as confidence tolerance master to the servant, to be subordinates. However, all decisions and set goals at the top of the unit. Some of the decisions taken in the framework of rewards and punishments prescribed at lower levels of employee motivation used for practical potential. Any interaction between supervisor and subordinate tolerance and leniency of the bosses and subordinates takes the fear and caution. While trans-round control in the hands of the leader of the delegation is focusing some lower average levels. Usually a non-formal form of resistance, but not always in front of goal.

Three Leadership Advisory: striking, but not full trust and confidence of the management of subordinates. While the general policies and decision taken at the higher level are also allowed to subordinates at lower levels in certain cases and specialized in their decision-making hierarchy communication up and down flow. Rewards and punishments random and partly to stimulate participation in the labor force is used. Balanced between supervisor and subordinate the actions and interactions that are often associated with confidence. Important aspect of process control is handed down and the two work in both high and low level of responsibility associated with. Informal organizations may take shape, but either confirms the objectives or partly refused resist.

The contributions of a group of four systems: In this kind of leadership subordinates, leader is confident with the decision widely distributed throughout the organization but is a unity. Communications not only up and down but also between groups is underway. Employee motivation as a result of their direct participation in determining economic rewards, goals, improving methods and evaluation of progress towards objectives will arise. Under the leadership of the extensive interaction between supervisor and subordinate, friendly and with a lot of confidence. In terms of process control and wide collective responsibility that lower units fully involved. Formal and informal organizations are the same. Therefore, all social forces in efforts to achieve organizational goals are to advocate action (Hersey and Blanchard, 1996, p. 76)

\subsubsection{Feedler's model}

Feedler's contingency theory of leadership that he has provided the leadership process is called a contingency model. This model suggests that the performance of the system of motivation and leadership style (workers or relationshiporiented) and the degree of control and influence, he is dependent on the situation after it became clear that the main leadership style or manner. The leader should be relevant to the position or status. According to Fiedler, to determine the factors that will determine the status or position, there is a contingent of three dimensions:

- The relationship between supervisor and subordinate: the trust, confidence and respect subordinates have caught the leader.

- The structure is about the extent to which the duties or tasks that need to be done, based on the set or organized.

- The leader of power or influence can be a leader on variables such as appointment and dismissal of employees, disciplinary regulations, enhance and enforce their rights.

- In this model, the eight possible combinations of these three variables can occur: 


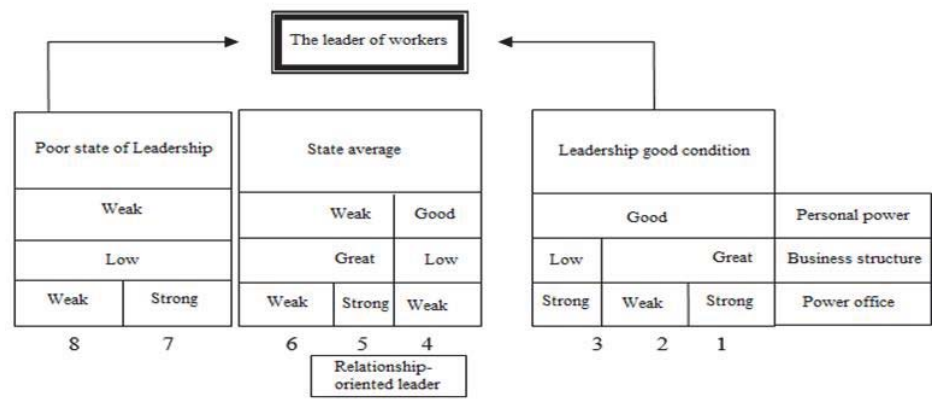

Figure (1): Predictions contingency theory of leadership. (Rezaeian, 2001, p. 394)

Feedler's tried to make the most effective leadership style (task-oriented or relationship-oriented) for each of the eight given situations. After reviewing previous studies and analysis of recent studies in the field of leadership concludes:

1. The leaders of the workers in those conditions favorable or unfavorable in lead better act.

2. Relationship-oriented leaders in positions of leadership are those of the utility better than average. (Rezaeian, 2001, p. 395)

From the perspective of Fiedler, genre or individual leadership style does not change. Therefore, only two ways that can lead to improved device performance. First, the leader can be chosen to suit the situation or circumstances that exist. Another way is to change the conditions governing the group, and it was the suitable and worthy leader. To do this, we can change the structure of the work to be performed or the amount of power that he could control agents (e.g., reduction of wages, promotion and implementation of Disciplinary Regulations) apply, reduced or added to, for example, based on Fiedler has been the leader in group 4. If he could increase its power, it will be able to group 3 and his suit was a condition that is the result of excellent performance. (Robbins, 2005, p. 656)

\section{Hersey and Blanchard's Situational Theory}

Situational leadership is a contingency theory that the followers and subordinates consider a leader emphasized that this is because the success or effectiveness of a leader lies in the fact that the followers who accept or reject the leader. Regardless of what the leader does, the success depends on how they are followers. The method presented Hersey and Blanchard. Based on the degree or level of preparedness of followers. Prepared to reflect the fact that pursuant to what extent a willingness and ability to carry out a duty. Hersey and Blanchard have identified four stages in the business of readiness.

1. In this stage, people are not willing or able to assume responsibility for the work.

2. Secondly, individuals have the ability to do things, but they are ready and willing to accept responsibility.

2. In this stage, people are able to work but do not want to do what the leader says.

3. The fourth stage people are capable and willing to do what they asked.

Fiedler's leadership position in the two dimensions that determine the behavior of the leader of their intended use or due to the employee's work.

However, Hersey and Blanchard thoroughly lose hold of even one step further, i.e. after at one end of the spectrum, and then combine them to create four specific leadership style.

- Command (due to excessive work due to low staff). The leader defines roles and tells employees what, how, when and where to do it. In this way, there are the instructions.

- Conversions (given a lot to do too much attention to the employee). To learn more about the individual leader with its mandate, but it still commands more attention to the person he is.

- Participation (low given much attention to the employee's work). Leaders and followers to participate in the decision-making plane. The main role of the leader is to expedite the work and communication.

- Representing the (little attention to the little attention to an employee). The work and the support of employees, the leader of any directive issued instructions not. (Ciriello, Marria.j, 1990) 


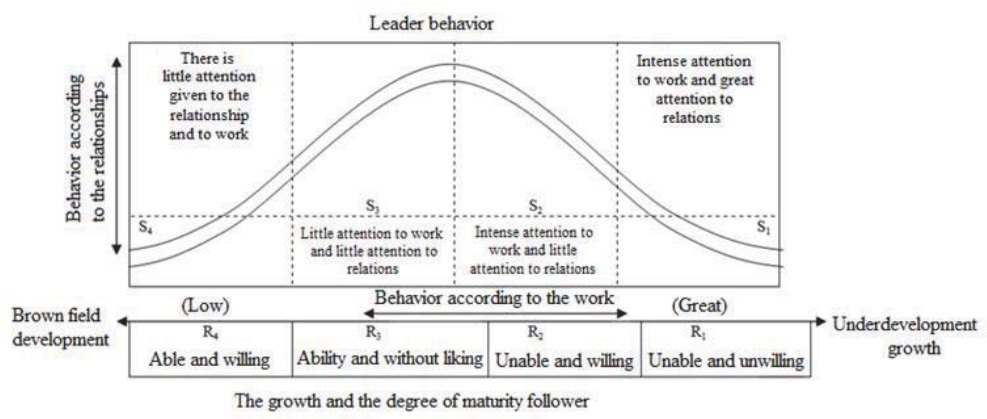

Figure (2): A model for Hersey and Blanchard's situational leadership. (Ciriello, Maria.j, 1990)

When followers to reach a high level of readiness, the leader not only of the degree of control over small things, but also trying to review their own behavior and the so-called less than the staff support, for example, in the first stage of preparation, the leader on and instructions known to his followers to give such instructions provided by the command leadership style. In the second stage, the leader should be a lot of work and employees. With extreme attention to the lack of readiness and capabilities of the employees will be compensated and with great attention to the staff, they are trying to mentally compensate friendships leader and wishes into action.

In the second step, motivational problems arise in the implementation of participatory leadership style; the best solution will eventually be the leader of the fourth stage of work to do too much, because followers tend to accept responsibilities as well as they can. (Ibid, p. 350)

\section{The Theory is Based on the Exchange of Views with Members of the Leader}

"George Graein" and his theory based on the exchange of views with the members gave their leader. In theory, it is argued that the leader of the pressures of time trying to establish a special relationship with a small group of subordinates. He formed a close group that they called non-formal or casual. Members of this group are trusted and have special privileges. The group's other members of the "official" or "other" called. Members of the intimacy of sex, age and personality are more compatible with the leader or the leader of the official with no significant heterogeneity. According to theory to predict based on the exchange of views with the members of a team leaders, "intimate" are much better; their movement is less and is more satisfied than his head. (Robbins, 2005, p. 4,663)

\section{Theory of Direction and Purpose}

The aim of the theory in the 1970s by "Martin" "Evans" and "Robert House" was coined, a contingency approach, but the focus and emphasis on the leader instead of constant characteristics, location and behavior of leaders. The theory provides the aim to conform to the position of a leader. The most important factor determining the capacity of the leadership and reward subordinates what to do to get the reward. The leaders can determine bonus's goals and ways to achieve them are clear. Style or way of effective leadership will be able to reward the employees who want or desire it.

The theory and purpose of four kinds of behavior as directive, supportive, cooperative and successful leader seeking to introduce.

- Directive leadership: what to expect from their leader to subordinates said. It provides guidance on how to do tasks, planning the work to be done, certain criteria in order to maintain the performance of subordinates.

- Supportive leadership behavior of friendly leader and social status, welfare and needs of subordinate's attention.

- Participative leadership: The leader on the subject of consultation with subordinates and considers their proposals before making a decision.

- Whether the successful leader: controversial effort to determine the objectives, expects from his subordinates at the highest level of effort and a lot of confidence that subordinates are trying to fulfill objectives.

- In theory direction and purpose, as Fiedler's contingency theory, it is assumed that any leader can be in a leadership position, one or all four leadership styles to apply. 
According to the theory of objective position on the relationship of two types of leader behavior influences subordinate's satisfaction.

- The personal characteristics of subordinates

- Environmental characteristics

Two important personal characteristics of subordinates include:

- Location and control source

- Perceived ability

Source control refers to the extent to which people think that what happened to him. As a result of his behavior or the result of external factors. The results show that people who rely upon consequences to their behavior tend to show more directive leadership. The ability to view individual perception refers to the ability to do something that has been entrusted to him. Employees who assess their own abilities are relatively high there is little likelihood that directive leadership to accept (figure3).

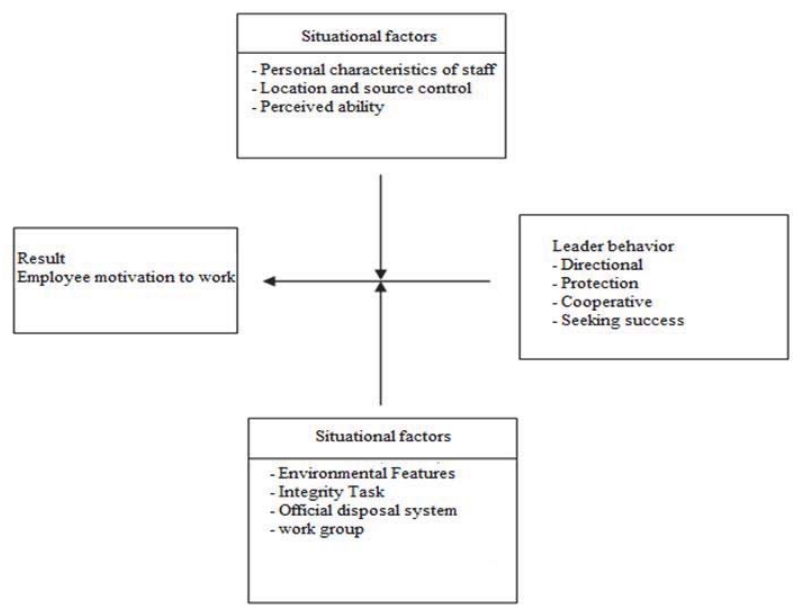

Figure (3): The theory of the goal. (Greephin, 2004, p. 364)

News important task cohesion, environmental characteristics, the systems of official and working groups are primary. According to the theory the target if the behavior of the leader to help employees cope with environmental uncertainty resulting from these factors will motivate the deal. However, in some cases, led to certain forms of waste and reduce the motivation of subordinates. For example, when the temperature is high task cohesion, directive leadership is needed less and less effective. Furthermore, if the frequency of the Working Group to provide social support, the supportive leadership will appeal. Therefore, it is assumed that leader behavior as individuals and situations that are in harmony with impact on motivation to do the job. (Greephin, 2004, p. 365)

\section{Participatory Leadership Model}

In 1973, "Victor Room" and "Philip yetan" collaborative leadership model provided the leadership behaviors associated with participation in the decision-making. This model shows that the structures for uniform and varied activities, are different. The researchers believe that leader behavior must reflect the corporate structure. Therefore, go and take your model as is the norm. Namely to determine the form and level of participation in decision-making, must be met to be exact set of rules and regulations in the different conditions of participation in decision-making change. The revised model has a variable decision tree consists of twelve and five leadership practices. This method of key variables related contingent leadership performance, cognitive integration that is based on the experience gained. In other words, participatory leadership model which recognizes that led research should be done to ensure one's own position. These are probably the most acceptable conditions and opportunities to talk to dictators and authoritarian and cooperative partnership. 


\section{Revised Situational Variables in Participatory Leadership Model}

(QR) Quality requirements: What is the importance of the technical quality of the decision?

(CR) requires the commitment of the importance of employee engagement is to decide?

(LI) Information Leader: Is an excellent decision, you have enough information?

(ST) of the problem: the problem of how adjusted (What type structure)?

(CP) Possibility commitment: If you have to take the decision alone, are you sure your employees will be committed to?

(GC) fit Aims: Are employees involved in determining the organization's goals are to fix the problem?

(CO) Employee conflict: whether there is a conflict between the employees to select reference solutions?

(SI) All employees, whether staff are excellent enough information to decide?

(TC) time limits: limited time if you are really serious, prevent employees' participation?

(GD) Geographic distribution: Does the cost of collecting geographically dispersed employees in a geographical area is justified?

(MT) Induction time: the time spent deciding what is important to you?

(MD) Motivation: How to maximize opportunities for staff development is important to you? (Ibid, p. 348)

\section{Five Leadership Practices in a Participatory Leadership Model}

Authoritarian: (I) according to the available information, problem solving or decision.

Authoritarian: (II) the information from his subordinates and then take action to solve the problem. He may, when seeking information from subordinates, make them aware of the problem or issue. The role that employees play in the process of decision-making, is to provide the necessary information and different solutions.

Consulting (I): a person with some subordinate's issue and brought together without them, takes their comments and suggestions, then decide to decide that may well reflect the opinions of subordinates and may it is not.

Consulting (II): individual sessions with employees, the issue with them and puts them aware of the comments and suggestions, then proceed to decide, which may be his decision, reflecting the views and suggestions of subordinates may no.

Group (II): individual meetings with subordinates so that all participate in problem-solving. They also suggest solutions and try to agree on a solution. (Robbins, 2005, p. 669)

Leadership partnership model to determine the form and level of staff participation in organizational decisionmaking through good when we put the feet. Moreover, empirical evidence available about the participation of employees in the following cases applies.

1. When decision quality is important.

2. While it is significant to accept that subordinate's solution allowing them to participate in decision making and that if not, it is unlikely that participate in decision-making and provide solutions.

3. When can the goals of the group to the attention of the employees to be trusted.

From the perspective of leadership or management style if the style is very limited as they Fiedler believes, because he could govern success and leadership shall wear appropriate amenities him. If researcher's opinion that the purpose and participative leadership theories have provided are correct. In that situation, what a leader should do, is that the clothes looked into the situation and adapt your leadership style or not.

\section{Management Systems}

\subsection{Likert leadership style}

"RenesisLickert" causal variables, mediators and end specify that in the debate about the effectiveness of implemented over time. The relationship between these three categories of variables can be triggered (the cause) on the organism (intermediate variable) act and a certain response (output variables) to create, to imagine that this relationship is shown in the following figure.

In this regard, we can say:

Management style as a variable cause, in other words, as the most important variable in the organization, perceptions, expectations, roles, trends and attitudes, traditions and methods of working groups, values, culture, goals, motivational forces and the behavior of individuals and the organization's staff affect, if the positive effects to the same level of trade and business organizations, increase productivity, reduce costs, increase sales and revenue will follow and 
the relationship between the organization and with other organizations and unions increased transfers, leave of absence and work among employees is also minimized.These variables in educational organizations about the richness of the learning process in schools and graduates with high-quality delivery at the community, no matter if the style managers within the organization and considering the variables to adopt and apply most likely will have negative effects on the variables and thus will act contrary to the above, in this case, perceptions, expectations, roles affected an increase turnover.

RenesisLickert and his colleagues at the University of Michigan Institute for Social Research, attention to human resources and capital resources as assets that require proper management and appropriate, have emphasized. Likert so many studies of organizational behavior, organizational change programs developed and implemented in various industrial facilities. The program aims to assist and help various organizations to the assumptions of the theory of $x$ toy shift their theory, the propagation behavior not to encourage growth and development of mature behavior and their growth and health of disciplinary focus on the factor's attention and help the satisfaction of working on their motives.

Likert studies found that traditional management styles can be on a continuum from system to system, four showed. It can be described as follows:

System 1: this type of management system to subordinates because they rarely have any confidence in the process of decision-making corporations. All decisions and goals of the organization at the head of the chain of command are carried out and taken down. Employees are forced by fear, threats, rewards incidental and physiological levels of satisfaction and work safety. Little interaction occurs between the supervisor, and subordinate are usually associated with fear and suspicion. Control process strongly focused on top management level is usually held under these conditions is a non-official which opposes the goals of the organization.

System 2: This type of trust and confidence with such as confidence tolerance master to the servant, to be subordinates. While all decisions and determine the objectives of the organization are carried at the head of some decisions taken in the framework prescribed at lower levels. Some potential rewards and punishments applied or used for employee motivation. Any interaction between the subordinate head with tolerance and leniency from the heads and with fear and caution done by subordinates.

While trans-round control in the hands of top management focus and a lower average level delegation of the others. Usually a non-official form, but always in front of the official goals of the organization is not resistance.

System 3: The management of a substantial but not full confidence, to be subordinates. While the general policies and decision taken at the higher level is also allowed into the hands of the lower-level cases to decide their very specific and specialized. Communication flows up and down the hierarchy.

Rewards, punishments, and to some extent, participate in the event are used to motivate workers.

Moderate mutual interaction between the subordinate's head often associated with moderate confidence. Important aspects of process control, and it handed down in both high and low levels is associated with a sense of responsibility. Informal organization may shape the organizational goals, but either confirms or partly resists it seeks.

System 4: In this type of trust and confidence expressed towards subordinates. Although the decision has been widely distributed throughout the organization but is a unity. Communications not only respects but also between groups and peers going up and down. Employee motivation as a result of their direct participation in determining economic rewards, goals, improving methods and evaluation of progress towards objectives will arise. Under this type of management, interaction between the subordinate head wide, friendly and with a lot of confidence. In terms of process control and wide collective responsibility that lower units fully involved. Formal and informal organization is one. Therefore, all social forces in efforts to achieve organizational goals are to advocate action. (Alaghehband, 1999, pp. 7 and 66)

In short, a system management (autocratic leadership) style task-oriented, imperative and development-oriented while four systems management (leadership group participation) is a relationship-oriented style that is based on teamwork and mutual trust and confidence. Two systems (benevolent autocratic leadership) and three (Leadership Advisory Board), styles between the two extremes above that were almost comparable with the theoretical assumptions of the theory of $x$ and $y$, respectively. (Ibid, p. 67)

Under the sovereignty of each of these systems. In the face of different and each one of the characteristics of the motivational forces, the interaction, the pattern of communications, process control, decision-making process and the process of setting goals is so different from the Likert theory It can be concluded that any organization which is actually a cooperative manner (style) management can bring a spirit of cooperation and to give them money, the best results will be achieved. (Stout, John, k. 1984) 


\section{New Theories of Leadership}

\subsection{Replace leaders}

In theory, the replacement of leadership: 1) individual characteristic, 2) task and 3) organizations can influence the ability to lead to satisfaction, and performances are superior to subordinates. In other words, if certain factors are present, one can without leaders, to do their assigned task. The alternative view leadership principles and contrary to traditional theories of leadership hierarchy was always considered important in many situations, the behavior of foreign leaders and the issue of an occasion.

1. Personal attributes: personal attributes that can defuse leader behavior include the ability, experience, education, knowledge, the need for independence, professionalism and attitude of indifference to rewards. For example, a person who has the ability and skills needed to perform his duties, and a high need for independence might lead to planning and structuring a leader who is not or the need for she said unhappy be hatred.

2. Details task: if the task is assigned to the staff, was routine and without coherence is high and the staff have always provided feedback on their performance. In other words, be aware of the consequences of their actions, and they can satisfy their inner motivation. This situation may lead to unnecessary and irrelevant behavior becomes a leader. Therefore, if a task can be enough to satisfy the needs of internal staff, so they need to support their leader.

3. Details of the organization: those characteristics of organizations that may be able to replace leaders are clear plans and objectives, regulations and procedures, working groups united and coherent, the exact structure of rewards and there is a physical distance between supervisor and subordinate.

For example, if the goals reflected in a clear and explicit job and work regulations, and multiple methods exist to do the job. The guidance may need to be a leader. (Greephin, 2004, p. 371, p. 2)

\subsection{Pragmatic leader and the leader of the cause of change}

In the latest research on leadership was divided into two categories. Leaders of the "pragmatic" leaders "creating transformation" Most theories like Ohio University research, Fiedler's model, the theory of the objective and collaborative management model, all the attention was pragmatic leaders. It guides its followers is leaders and stimulates them altogether and causes the organization's objectives will be met.

Transformational leaders, the ones who inspire his followers, can give them spiritual guidance and direction provided that the interests of the organization. They can also cause that subordinates acted with high spirit and profound effects on their organizations. Their subordinate's special attention to the needs and progress of the advanced features, they add to knowledge and can be conducted in a way that people from new perspectives to old problems look. In the shadow of stimulating and motivating people, they are encouraged to the so-called source of their own lives and do not spare no effort to meet the goals of the organization. Features include two categories of leaders:

Pragmatic leaders

Contingent rewards: According to the contract, the amount of compensations based on their performance, attention and commitment to practices that are not appropriate rewards for good performance.

Exception-based management (active): Note that the work standards and regulations and in case of deviation seeks corrective actions to come.

Exception-based management (passive): intervene only when the standards are not observed.

Chaos: responsibilities leave, do not take any decisions.

Leaders who are creating change.

His Majesty in his mind an interesting picture of the people and are responsible for such an important mission altogether. The people's belief that they respect their heart, they are proud of their own, and they have confidence.

Inspire: hope and the promise of so much to focus attention on some of the gestures they use, the simple expression of great goals and objectives speak.

It adds the following insight: increased knowledge and insight are followers, the self-oriented and to solve problems and to comply with their instructions carefully.

The individual will personally handle issues: special attention is required in each of the employees and subordinates, as a coach, and the recommendations of the projects.

The two leaders (pragmatic and causing upheaval) have two ways of doing things are opposite or contradictory. 
When progress reaches a peak, pragmatic leader for leadership is entrusted to him or causing called evolution. Usually practiced by so-called leaders are the deposit and the type of work or their efforts beyond pragmatic management of subordinates. Beyond that, a change in the leadership of the charismatic leader is nothing more than.

According to one expert: Probably a charismatic leader from his followers, demanding that the new vision and creative look at your world and your feet do not exceed this limit, but a leader who brings people constantly trying to change this idea in mind his followers whom they had injected power and superior capabilities, and We should not only look at current issues and to support new perspective on things, but rather from a particular angle and prospective leader sees things; issues be considered. (Robbins, 2005, pp. 7 and 686)

\subsection{Definition of job satisfaction}

Job satisfaction is define dinterms of effectiveness and efficiency. Effectiveness of Organizational Behavior agreement with organizational expectations and performance is a function of the agreed organizational behavior to the needs and personal goals.

Satisfaction refers to the relationship between organizational expectations and individual needs. Infact, when consent would be desirable expectations and beconsistent with the needs and desires of the agreement (Alagheh band,1999, p.103)

The "Dayvis"and "Niveastroom" job satisfaction, consistentset of feelings about the job. This feeling is obtained when the desires, needs, aspirations and experiences that your organization is working on arrival to be met through work. As such, they balance between meeting the expectations of employees and as a result employees have a positive attitudeto the job that he is satisfied.

Generally speaking, five major factors that are considered as dimensions of job satisfaction:

1. Payment: of salary and fairness in pay

2. Occupation: extent to which job tasks, provide opportunities for training and responsibility.

3. Promotion opportunities: access to opportunities for advancement

4. Head: the ability of the supervisor to demonstrate interest in employees

5. Cooperation: partners so friendly, competent and supportive. (MOGHIMI, 1998, p. 391)

\subsection{Teachers}

For teachers who have been teaching in the high schools' for girls'.

Shahed Schools ${ }^{1}$

According to the division between the schools, including public schools, schools of public, community model schools, talented students and schools from these schools to schools inform the witness that assuming Regulations and prioritize and privileges stipulated by the Registration Committee to provide expert witness.

Non shahed students may be eligible to register according to the total scores to be avoided, and If you register on the top-rated capacity is over it's time to enroll students ranked lower and These students should not be registered in other schools.

\section{Background Research}

- "MacKay" leadership in research as heads of public colleges and job satisfaction by examining reports of 321 public colleges, came to the conclusion that high job satisfaction, leadership positively with "relationshiporiented, high, low conscientiousness " connected. Job satisfaction between men and less professional staff. (McKee, 1991)

- "Heller" and reported that "Hersey and Blanchard" The research on the relationship between leadership styles (command, participation and empowerment) and job satisfaction was teachers who responded; $42 \%$ of 339 teachers are dissatisfied with their jobs. I Furthermore, found that fewer teachers are satisfied with salary and benefits, and more cooperation will lead to their satisfaction. In this study, job satisfaction was significantly

${ }^{1}$ School child of the martyrs and veterans was created in order to empower Shahed to protect the dignity of the martyrs, service beyond the usual granted to their children. Schools often Shahed both in terms of educational and cultural programs for emergency and public schools are better. Especially those who Shahed the schools, religion and such schools for those who have religious concerns, is appropriate. 
correlated with leadership style. (Heller \& other, 1993)

- $\quad$ A study conducted by (Pulvino, Carol Ann Fox) in 1979 at the American University of Wisconsin-Madison and friendly relationship between human behavior and the motivation of the teachers were studied the results showed that the friendly relationship manager due to the sentiments and wishes of teachers is an important factor in motivating and encouraging them. Another result of this study was to indicate the participation of teachers in decision-making a huge impact on the motivation of teachers. (MoradEbrahimPour, 1999, p. 112)

- A study conducted by Bahraloloom, the relationship between organizational culture and management style and job satisfaction of physical education experts has been working in Tehran. The results of this study show that there is a negative correlation between gender and job satisfaction, but not significant. But not significant positive correlation between marital status and job satisfaction. There is a significant negative correlation between education and job satisfaction. Between work experience and job, satisfaction is positively correlated. Significant negative correlation between educational level and job satisfaction. There is no significant correlation between employment status and job satisfaction. Significant correlation between organizational culture and job satisfaction and organizational culture, job satisfaction explains 0/33 of changes between management style and job satisfaction were significant positive correlations between leadership style and organizational culture; job satisfaction is positively correlated. (Bahraloloom, 1999).

\section{Development of Hypotheses and Model}

Variable criteria: leadership styles based on the Likert theory of authoritarian / exploitative, authoritarian / charity, consultation and participation.

Predictive variables: job satisfaction of teachers in in shahed high schools' for girls' in Tehran in the academic year 2014-2015

Unwanted variables: age of the teachers and the salaries of teachers and the incentives and rules and regulations and regulations and the level of education and sex education and school partners

Moderating variables: gender / female teachers and the school year 94-93

Now, summing up the theories and empirical research findings cited research provided the theoretical model.

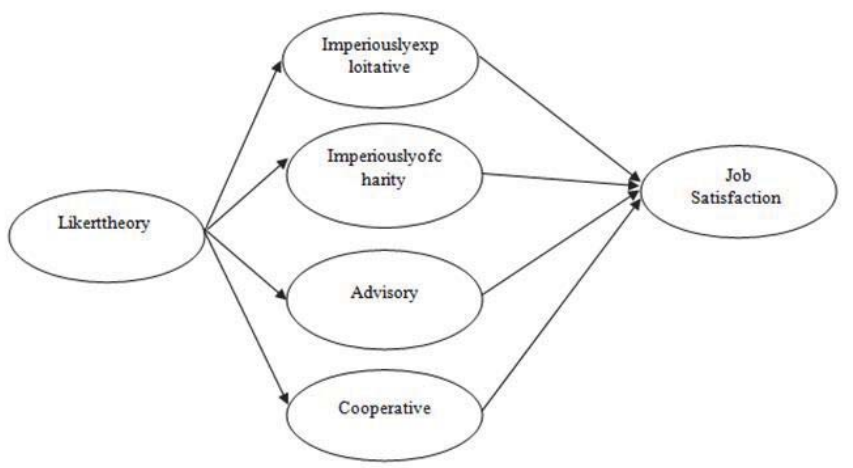

Shape (1): Conceptual Model

\section{Methodology}

In this study, a questionnaire was used for data collection and reliability of the questionnaire through Cronbach's alpha was calculated and used questionnaires include "leadership style questionnaire with reliability 0/8203", "Minnesota questionnaire that has high reliability and validity was used. "

Leadership style questionnaire containing 27 questions, each question has organized independent and five options (very high, high, to some extent, low and very low) and each style has its own questions, which are:

The first secondary study hypothesis or Likert leadership style: (between Imperiously leadership style / exploitation job satisfaction of teachers in there). 
Question 1. To what extent to implement the directives and regulation's principal stresses?

Question 2. The principal question of how much you want in the research objectives of teachers work hard?

Question 3. Ask your principal how much you demand the imperative and voice commands?

Question 4. How much principal you adjust the program of work to be done?

Question 5. The school principal asked teachers how much you want to standards, rules and regulations are strictly observed?

Question 6. Ask your school principal to the teacher's sensitive to the presence or absence and the presence of early is recommended?

Question 7. The principal question is how far you take action without consulting the teachers?

The second secondary study hypothesis or Likert leadership style between authoritarian leadership style / charity with job satisfaction of teachers there.

Question 1. To what extent the principal secretary his own expectations?

Question 2. The principal question of how much you are willing to act as a spokesman for the teachers?

Question 3. To what extent the principal decisions to the school's administration council?

Question 4. The principal question how much you will use the incentives happened?

Question 5. The principal question is how much you tried to impose their views in favor of their teachers and students?

Question 6. The principal question is how much the desirability of the result of the teachers, they appreciate it?

The third secondary study hypothesis or Likert leadership style: (consultative leadership style and job satisfaction among teachers there)

Question 1. To what extent the principal decision-maker's teachers to work?

Question 2. The principal question of how much you do things according to the responsibility of everyone monitor is entrusted to teachers?

Question 3. How much the principal you like to change in order to improve the school?

Question 4. To what extent school principals and teachers to work out effective work provoke?

Question 5. To what extent the principal shared his views with the teachers and the reaction they informed?

Question 6. The principal question is how much teachers are encouraged to do better?6 The principal question is how much teachers are encouraged to do better?

The fourth secondary study hypothesis or Likert's leadership style (between participatory leadership style with teacher job satisfaction are related.

Question 1. The principal question of how much you trust the teachers?

Question 2. The principal question is to what extent the participation of the teacher motivates you?

Question 3- to freedom that teachers do?

Question 4. To what extent are the principal human aspects of work and pleasure teachers take into consideration?

Question 5. The principal question is how much of rewards and recognition by the determination work?

Question 6. How friendly is the principal and teachers to accept with open arms?

Question 7. The principal question of how much you may have the opportunity to listen to the teacher talk?

Question 8. Ask your school principal to what extent the judgment of teachers in educational matters and student discipline confident?

The second survey, the job satisfaction of teachers from their jobs examined the standardized questionnaires and "Minnesota" is. The questionnaire, in 1967 at the State University of Minnesota by Mindy "Davidj, weiss, Rene V.Dawis, George W.England and LioydH.Lofquist" has been developed. 20 main measures of different aspects of the job in the questionnaire, which included respondents rate their satisfaction on a range of five options, including "I'm very happy; I'm happy; I do not know; I'm not happy; I am very satisfied," specify. The questionnaire, job satisfaction of teachers with regard to various aspects of the school environment and outside it, such as teachers' relationships with each other, relationships with teachers, supervisors and managers, pension and benefits, the implementation of educational policies, job security, progress career decision making on issues of social prestige job and succeed in the job, evaluated and measured.

In this study,the sample size in this studyusing the "Morgan _ Takman"of the 201 teachers working in 11 schools,133 were determined Shahed high schools for girls because the population is made up only of women as a result of all the participants were selected from a gender and to select a sample group of 133 persons and the random sampling method is used according to population size and random process that lead to the fact that the sample group represents the community to have more confidence. (Hooman,1994,p.15) According to statistics provided in the academic year2014- 
2015 target population included 201 teachers.For stratified random sampling in Tehran divided into 5 parts as follows.

Table (1): Sample perineacharea of tehran

\begin{tabular}{|c|c|c|c|}
\hline The sample sizefor each region & The total number ofteachers inarea & Areas & Educational regions \\
\hline 23 & 34 & 3,1 & North \\
\hline 24 & 36 & $19,16,15$ & South \\
\hline 48 & 73 & $13,12,4$ & East \\
\hline 9 & 15 & 10 & West \\
\hline 29 & 43 & 6,2 & Center \\
\hline 133 & 201 & & Sum \\
\hline
\end{tabular}

After determining the number of teachers in each region based in the schools in each region, each district school teacher was selected randomly distributed between them.

In this study, to investigate the relationship between leadership style and job satisfaction of the Pearson correlation coefficient was used as the secretary of the score in the questionnaires both the shell and leadership style and job satisfaction is that we want to compare them. Delaware explains it says:

Correlation method is used when the variables are continuous. Such tests of mental development and achievement test that is, each person will have two scores in the two tests.

In order to examine the relationship between demographic characteristics such as education teachers, teaching experience, age and job satisfaction of ANOVA and characteristics such as marriage or singleness of t_test will be used.

\section{Data Analysis}

Table (2). Likert's correlation between leadership styles and job satisfaction

\begin{tabular}{|c|c|c|l|}
\hline Number & The level of significance & Correlation & Leadership style \\
\hline 85 & $0 / 253$ & $0 / 125$ & Predatoryexploitation \\
\hline 83 & $0 / 137$ & $0 / 165$ & Imperiouscharity \\
\hline 85 & $0 / 000$ & ${ }^{\star \star} 0 / 509$ & Advisory \\
\hline 78 & $0 / 000$ & ${ }^{\star *} 0 / 587$ & Cooperative \\
\hline
\end{tabular}

(In the above table marked "**" means alpha is 0/01)

Statistics The table above shows that between exploitative autocratic leadership style and job satisfaction, there is no significant relationship. The benevolent autocratic leadership style and job satisfaction there is no significant relationship. The consultative leadership style and job satisfaction at the significant level (0/01) there is a positive and significant correlation. Significant and positive relationship between participatory leadership style and job satisfaction at the significant level (0/01) there.

Table (3). Correlations between leadership styles of each of the factors of job satisfaction

\begin{tabular}{|c|c|c|c|c|c|c|}
\hline \multirow[t]{2}{*}{ Promotion } & \multirow[t]{2}{*}{ Condition } & \multirow[t]{2}{*}{ Nature of work } & \multirow[t]{2}{*}{ Collaborators } & \multirow[t]{2}{*}{ Supervision } & \multirow[t]{2}{*}{ Law } & job satisfaction \\
\hline & & & & & & Leadership style \\
\hline${ }^{\star} 0 / 234$ & $0 / 025$ & **0/285 & $0 / 170$ & $-0 / 056$ & $-0 / 012$ & Predatoryexploitation \\
\hline${ }^{\star} 0 / 232$ & $0 / 131$ & $0 / 099$ & $0 / 123$ & $0 / 111$ & $0 / 121$ & Imperiouscharity \\
\hline **0/492 & **0/454 & **0/405 & **0/314 & **0/597 & *0/192 & Advisory \\
\hline$\star \star 0 / 430$ & $\star \star 0 / 388$ & $\star \star 0 / 437$ & ${ }^{\star \star} 0 / 326$ & ${ }^{\star \star} 0 / 641$ & $0 / 101$ & Cooperative \\
\hline
\end{tabular}

(In the above table marked "*" means alpha 0/05 and marked "**" is meant alpha 0/01)

The above correlation between leadership styles of each of the factors of job satisfaction includes "rights, supervisors, colleagues, the nature as the work, and promotion" were investigated and the results are as follows.

(A) The exploitative autocratic leadership style with the nature of work and the promotion of positive and significant correlation exists and the rights of co-curator and Condition, there is no significant relationship.

(B) Benevolent autocratic leadership style with the promotion of the relationship between low and there is a significant level of 0/05 and there is no association of other factors. 
(C) A consultation with the Leadership style of supervision, Collaborators, the nature as the work, and promote a positive and significant relationship and there is a significant level of 0/01 and 0/05 of the law, there was a significant relationship between low and level.

(D) There is a significant correlation between rights and participatory leadership style of supervision, et al nature as the work, and promoted there is a significant relationship between participatory leadership style, and 99\% say there is a significant relationship with job satisfaction factors.

\subsection{Examine the relationship between demographic characteristics of teachers with job satisfaction}

According to the results of spss software between personal characteristics, including education teachers' experience, teaching experience in schools to see, age, marital status and job satisfaction in the sense that there was no relation between female teachers in control schools being married and or single, young or experienced, the low- and high teaching experience and level of education have no effect on their job satisfaction.

\subsubsection{The main hypothesis of the research}

"Likert between leadership style and job satisfaction of teachers from the perspective on the target population, there is a significant relationship."

According to the results obtained from the software program spss according to Table (4) Likert leadership style and job satisfaction among teachers in the population, there is a significant positive relationship.

Table (4). The main hypothesis test

\begin{tabular}{|c|c|c|c|}
\hline Confidence level $(\mathrm{p})$ & Levelerror $^{(\alpha)}$ & Correlation & Hypothesis \\
\hline$\% 99$ & $0 / 01$ & $0 / 545$ & The first main \\
\hline
\end{tabular}

As a result, one can say with $99 \%$ from the perspective of teachers, the school principal Leadership style and management of a significant relationship with job satisfaction of teachers there.

\subsection{Secondary research hypotheses:}

"Exploitative autocratic Leadership style of managers with job satisfaction among teachers in the target population, there is a significant relationship."

According to information given to the program spss software Table (5) the exploitative autocratic leadership style Likert's job satisfaction of teachers in the study sample, there is no significant relationship.

Table (5). First secondary hypothesis test

\begin{tabular}{|c|c|c|c|}
\hline Confidence level $(\mathrm{p})$ & Levelerror ${ }^{(\alpha)}$ & Correlation & Hypothesis \\
\hline$\% 99$ & $0 / 01$ & $0 / 125$ & first secondary \\
\hline
\end{tabular}

According to the above table and minor study does not confirm the first hypothesis.

"Between the benevolent autocratic Leadership style of managers with job satisfaction of teachers in the target population, there is a significant relationship."

Using the software program spss, the benevolent autocratic leadership style and job satisfaction of teachers Likert Pearson correlation coefficient was used, which results in accordance with the table (6) is.

Table (6). Second secondary hypothesis test

\begin{tabular}{|c|c|c|c|}
\hline Confidence level $(p)$ & Levelerror $(\alpha)$ & Correlation & Hypothesis \\
\hline$\% 99$ & $0 / 01$ & $0 / 165$ & second secondary \\
\hline
\end{tabular}

Statistics The table above shows that the second hypothesis is not confirmed, the research subsidiary of the benevolent autocratic leadership style Likert's job satisfaction of teachers in the target population, there is a significant relationship. 
"Consultation between managers' Leadership style job satisfaction of teachers in the target population, there is a significant relationship."

The Pearson correlation coefficient obtained by spss software Table (7) of teachers says their job satisfaction and Leadership style advisory except significant positive relationship.

Table (7). Third secondary hypothesis test

\begin{tabular}{|c|c|c|c|}
\hline Confidence level $(p)$ & Levelerror $^{(\alpha)}$ & Correlation & Hypothesis \\
\hline$\% 99$ & $0 / 01$ & ${ }^{*} 0 / 509$ & third secondary \\
\hline
\end{tabular}

The third secondary confirmed the hypothesis.

"Participatory leadership style of managers with job satisfaction among teachers in the target population, there is a significant relationship."

The result of spss software in accordance with the table (8) is as follows.

Table (8). Fourth secondary hypothesis test

\begin{tabular}{|c|c|c|c|}
\hline Confidence level $(p)$ & Levelerror $(\alpha)$ & Correlation & Hypothesis \\
\hline$\% 99$ & $0 / 01$ & ${ }^{\star} 0 / 587$ & fourthsecondary \\
\hline
\end{tabular}

According to the table above, we can say with $99 \%$ confidence between Likert participatory leadership style and job satisfaction of teachers in the target population, there is a significant positive relationship between fourth sub-research hypothesis is confirmed.

\section{Conclusion}

In summary, the results of research hypotheses were as follows:

- The main hypotheses as to the leadership style of Likert's view job satisfaction of teachers in society there is a significant statistical relationship the test was conducted with respect to the Pearson correlation coefficient obtained by SPSS in 0/545 amount is significantly 0/01 and the larger the critical factor. Therefore, the null hypothesis is rejected, and the research hypothesis is that the first hypothesis is confirmed. This means that a significant relationship exists between leadership style and job satisfaction of teachers.

- The first secondary hypothesis minor study that autocratic leadership styles _ exploitative Likert's satisfaction of teachers in the target population, there was a significant relationship between the results obtained SPSS software as the Pearson correlation coefficient obtained from the coefficient of the critical value is $0 / 125$ to $0 / 01$ error is smaller the research hypothesis is not confirmed the relationship between autocratic leadership style / exploitation Likert's job satisfaction of teachers in the target population there.

- On the second secondary hypothesis benevolent autocratic leadership style, Likert's study says the job satisfaction of teachers in the target population was significant it can be said with regard to the results obtained by Pearson's correlation coefficient 0/165 SPSS software is that it is smaller than the critical factor not confirm this assumption. This means that the relationship between job satisfaction of teacher's autocratic style-exploitation Likert there.

- The third secondary hypothesis premise of research sub-advisory Likert Leadership style and job satisfaction among teachers in the target population, there was a significant relationship, according to results from SPSS, the Pearson correlation coefficient obtained 0/509 and because 0/01 when the error level is larger than the critical factor is the assumption behind the study confirmed the positive relationship between job satisfaction of teachers Likert Leadership style is consultative.

- Suppose fourthsecondary hypothesisstudy that the job satisfaction of teachers in participatory leadership style Likert's target population was significant. That according to results from SPSS software, 0/587 correlation coefficient that is as significant in the larger table is supposed to work 0/01 coefficient confirmed the positive relationship between job satisfaction of teachers in participatory leadership style Likert the target population in the 2014-2015academic year is available.

Overall, this study shows that authoritarian styles - colonial and authoritarian charitable Likert, There are not any 
job satisfaction and style consultation and participation Likert, There are not any job satisfaction and style consultation and participation Likert satisfaction Teachers', there is a significant relationship and this means that the quality of leadership in the different processes throughout an organization such as the method of decision-making, communication, interaction, group members create favorable conditions of work, individual needs and achieve organizational goals and the most significant effect. Therefore, it deserves it is considered as one of the components of job satisfaction into account. The correlation between leadership style and job satisfaction results over the past, such as the Research University of Michigan, Hoy and Myskel is supported by research.

\subsection{The other findings from the study}

Other findings included the relationship between each of the Likert leadership styles (autocratic-colonial, authoritarian, benevolent, consultation and participation) with each of job satisfaction factors include (salary, supervisors, colleagues, the nature as the work, and promotion) that the are discussed below.

Rights factors of job satisfaction among only a consultative leadership style, and at a significant level, there is little connection 0/05 and there is a significant relationship to the leadership style of rights and therefore, cannot be influenced by the style of leadership and the reason for this could be due to the same rights education among teachers and the principal of non-interference in the rights of the teachers.

Between job satisfaction and Leadership style of supervision of 1 (authoritarian-exploitation) and light-emitting diodes 2 (authoritarian - benevolent) there is no significant relationship between the leadership style 3 (Advisory) and Leadership style 4 (participatory) positive and significant correlation exist and the correlation coefficient among all the factors of job satisfaction due to participatory leadership style led by a factor of job satisfaction (0/641), which indicates that the most common factors that influence job satisfaction of teachers in the target population directly affected and positive behavior is director.

Collaborator's factor of job satisfaction and Leadership style between 1 and 2 there is no significant relationship and there is a positive significant relationship with Styles 3 and 4 and this means that no matter how consultative and participatory leadership style would be more satisfied collaborators. Between the nature of work of job satisfaction and Leadership style 1, 3 and 4 was significant and only 2 no relationship with Leadership style that the comparison between autocratic leadership style - exploitative autocratic leadership style - can be benevolent autocratic leadership style exploitative nature as the work of the teachers' job satisfaction and further strengthen the feeling of provide more satisfaction.

The Condition factor of job satisfaction and Leadership style 1 and 2 there is no significant relationship and 3 and 4 correlated with Leadership style and there is a direct consultative and participative leadership style is that no matter how working conditions for teachers will be more satisfactory.

Among the professional improvement factor of job satisfaction and Leadership style 1 and 2 there are little correlation and 3 and 4 leadership style and there is a direct correlation, which means that leadership style had a little impact of the promotion of employment of job satisfaction.

Another finding of the study sample included the relationship between the characteristics within the individual (education, experience, teaching experience in schools, control, age and marital status) and job satisfaction of teachers in the target population, which is discussed as follows: Regarding education, there must be said though some studies show a negative relationship between education and job satisfaction because no matter how higher-education level and knowledge level to the population is expected and in the same situation, but less satisfied by the result from this study showed that there was no relationship between the level of education with job satisfaction.

The teaching experience and teaching experience in the control schools, according to information obtained by SPSS no relation was found between job satisfaction and teaching experience.

The relationship between independent variables and the dependent variable age, job satisfaction should be noted that although the results from some studies show that increasing age is on everyone's experiences and this factor makes them a realistic vision to find work, and their expectations were lower and more consistent with the work environment itself, but research suggests no significant relationship between and job satisfaction, there is no age of. Furthermore, single or married teachers are not associated with job satisfaction.

\section{Offers}

- It is recommended for managers to understand the characteristics, needs, interests and level of maturity and responsibility of their subordinates, and in accordance with their existing organizational circumstances, to 
choose the appropriate style of leadership and motivation and satisfaction among staff unions.

- Since the results from this study, the relationship between leadership style and job satisfaction confirms the consultation and participation. It is recommended with in-service training and other means, awareness and managers to enhance their leadership style and leadership that have encouraged the styles they use.

- Strengthening the group to the form of Council decisions in accordance with the possibilities and limitations of teachers for working conditions is recommended.

\section{References}

Abbaszadegan, Seyed Mohammad: The basic principles of organization and leadership, printing, publishing Publishing Corporation, 1997.

Alaghehband, Ali: General Management, Fourth Edition, Tehran, mental Publishing, 1999.

Bahraloloom, Hossein relationship between organizational culture and management style and job satisfaction of physical education specialists working in Tehran, Faculty of Physical Education Teacher Training University, 1999.

Ciriello,Marria.j,catholic School teachers viws of Job Satisfaction and Word Cirumstances and the Relationship to Commitment, Boston, 1990.

Greephin, Moorhead: organizational behavior, translation Seyed Mehdi Alwani and GholamrezaMemarzadeh, Eighth Edition, Tehran, Pearl, 2004.

Heller,H.William, and others, the Relation shipbitweentheacher Job satisfaction and principal Leadership style, 1993.

Hersey, Paul and Kenneth Blanchard: management, organizational behavior (the use of human resources), translated by Dr. Ali Alaghehband, twelfth edition, Tehran, Amir Kabir Publishing Institute, 1996.

Hooman, Haydar Ali: The statistical inference in behavioral research, Tehran, 1994.

Hoy, Wayne. Myskel, Sisley: Theory, research and practice in educational management, translation Abbaszadeh, Mir Mohammad, printing, Urmia. 1992.

Mckee,JaneGallimore, Leadership Styles of Community College Presidents and Faculty Jof Satisfaction, Jan Mar, 1991.

Mir Kamali, Seyed Mohammad: Leadership and Educational Management, Fourth Edition, published Ramin, 1996

MoradEbrahim Pour Mehrdad: examine the relationship between anxiety and depression management style with high school teachers in city of Sabzevar, Master Thesis, Faculty of Education and Psychology, ShahidBeheshti University, 1999. MOGHIMI, Seyed Mohammad: organization and management (research approach) cashmere Publications, Tehran, 1998.

Pardakhtchi, Mohammed Hassan: "educational management as a professional field," Journal of Management Education, No. 3, Spring 1994

Rezaeian, Ali, principles of organization and management, Tehran, the, 2001, First Edition

Robbins, Stephen P. following: organizational behavior, PARSAEIAN translators Ali and Mohammad Arabs, Volume II, Sixth Edition, Tehran, Cultural Research Bureau, 2005.

Stout, John, k. Supervisors,structucturing and Consideration Behaviors and Workers, Job Satisfaction, Stress, and Healt problems, 1984. 